\title{
Correlations of Human Epithelial Growth Factor Receptor 2 Overexpression with MUC2, MUC5AC, MUC6, p53, and Clinicopathological Characteristics in Gastric Cancer Patients with Curative Resection
}

\author{
Kwang Kuk Park, ${ }^{1}$ Song I Yang, ${ }^{1}$ Kyung Won Seo, ${ }^{1}$ Ki Young Yoon, ${ }^{1}$ Sang Ho Lee, ${ }^{1}$ \\ Hee Kyung Jang, ${ }^{2}$ and Yeon Myeong Shin ${ }^{1}$ \\ ${ }^{1}$ Department of Surgery, Kosin University College of Medicine, 34 Amnam-dong, Seo-gu, Busan 602-703, Republic of Korea \\ ${ }^{2}$ Department of Pathology, Kosin University College of Medicine, 34 Amnam-dong, Seo-gu, Busan 602-703, Republic of Korea \\ Correspondence should be addressed to Yeon Myeong Shin; sym@ns.kosinmed.or.kr
}

Received 9 July 2014; Revised 29 September 2014; Accepted 18 October 2014

Academic Editor: Zhongxia Wang

Copyright (C) 2015 Kwang Kuk Park et al. This is an open access article distributed under the Creative Commons Attribution License, which permits unrestricted use, distribution, and reproduction in any medium, provided the original work is properly cited.

Background. The purpose of this study was to evaluate the relationships between HER2 overexpression in the tumor and MUC2, MUC5AC, MUC6, and p53 status and clinicopathological characteristics of gastric cancer patients. Methods. This retrospective study included 282 consecutive patients with gastric cancer who underwent surgery at the Kosin University Gospel Hospital between April 2011 and December 2012. All tumor samples were examined for HER2 expression by immunohistochemistry (IHC) and MUC2, MUC5AC, MUC6, and p53 expression by staining. A retrospective review of the medical records was conducted to determine the correlation between the presence of HER2 overexpression and clinicopathological factors. Results. The HER2-positive rate was $18.1 \%$. Although no association was found between HER2 expression and MUC5AC, the expression of MUC2, MUC6, and p53 was significantly correlated with HER2 positivity, respectively $(P=0.004,0.037,0.002)$. Multivariate analysis revealed that HER2 overexpression and nodal status were independent prognostic factors. Conclusions. HER2 overexpression in gastric carcinoma is an independent poor prognostic factor.

\section{Introduction}

Gastric cancer is still one of the most common and aggressive carcinomas throughout the world with a high mortality, especially in South Korea. At present, an HER2-based concept of tumor biology has been established, and trastuzumab (Herceptin, Genentech/Roche), a monoclonal humanized antibody directed against HER2, is a pivotal agent for the management [1]. In gastric cancer also, many publications have suggested a similar role of HER2 [2-7]. Although many studies have previously evaluated HER2 status in gastric cancer, the patient cohorts and scoring criteria have varied, resulting in discrepancies in HER2 positivity that have ranged from 8.2 to $53.4 \%$ [8]. The trastuzumab for gastric cancer (ToGA) trial has assessed HER2-targeting agents for treating advanced gastric cancer $[9,10]$. HER2 evaluation becomes an important approach for predicting patient response to HER2-targeting agents. Regarding the clinicopathological features of HER2-positive gastric cancer, HER2 expression and intestinal histological type have shown a high correlation.

When focusing on the cellular origin or differentiation of gastric adenocarcinoma, the expressions of different types of mucins are used as epithelial differentiation markers. Mucins are high molecular weight glycoproteins with oligosaccharides attached to serine or threonine residues of the mucin core protein backbone by O-glycosidic linkages. Mucins can be classified into two categories: transmembrane mucins (MUC1, MUC3, MUC4, MUC12, MUC13, MUC15, MUC16, MUC17, MUC20, and MUC21) and secreted mucins (MUC2, MUC5AC, MUC5B, MUC6, MUC7, and MUC19) [11-13]. The mucins are produced by various epithelial cells and serve protective and lubricating roles. However, in damaged 


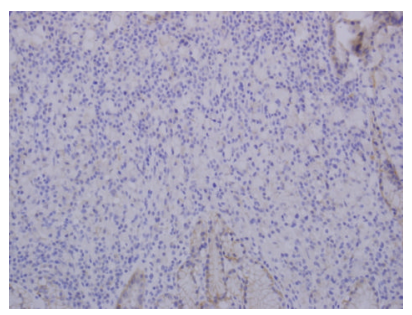

(a)

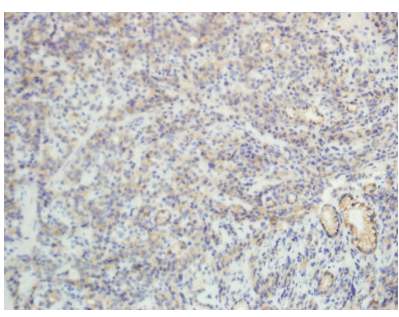

(b)

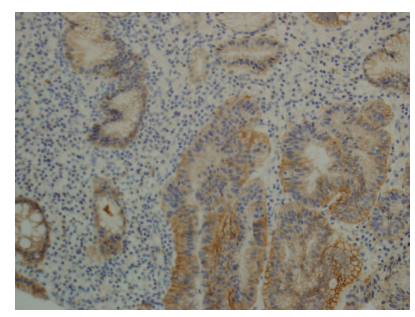

(c)

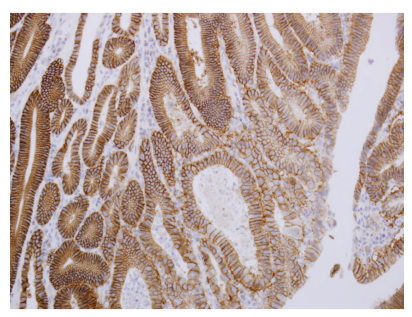

(d)

FIGURE 1: Immunohistochemical analysis of human epidermal growth factor receptor 2 protein expression (a-d). (a) Immunostaining shows no staining on tumor cell membrane. (b) Immunostaining shows positive reaction (1+). (c) Immunostaining shows positive reaction (2+). (d) Immunostaining shows positive reaction (3+) with complete or basolateral membraneous staining.

epithelia or tumor cells, there is a loss of polarity that occurs in association with the activation of a proliferation and survival program [14]. Mucin gene expression is relatively organspecific, and deregulated expression of one or more types of mucins occurs with malignancy $[15,16]$. MUC5AC and MUC6 are markers of gastric foveolar cells and antral/cardiac mucous glandular cells, respectively, and they reflect gastric phenotypes. MUC2 exhibit the typical intestinal epithelial cell phenotype, decorating goblet cells and the brush border of intestinal absorptive epithelial cells, [17]. However, the relationship between HER2-positive gastric cancer and mucins was unclear.

The $p 53$ tumor suppressor gene is the most commonly mutated gene in human tumors [18]. Abnormalities of the $p 53$ gene have been identified in many malignancies, including gastric carcinomas [19]. The major functions of p53 protein are regulation of the cell cycle and apoptosis and repair of DNA damage. Functional abnormality of $\mathrm{p} 53$ is known to be caused by mutation of the $p 53$ gene, including loss of heterozygosity (LOH) and DNA methylation, [20] which can affect the biological behavior of the tumor and therefore prognosis.

Although some studies have shown a correlation between HER2 expression and p53 nuclear staining, little is known about the relationship between HER2 positivity and mucins and $\mathrm{p} 53$ expression $[19,21]$. The purpose of this study was to evaluate the frequency of HER2-positive gastric cancer, by applying the standard scoring criteria in patients with gastric cancer and the relationships between HER2 expression and prognosis, mucins, p53 overexpression, and other clinicopathological features.

\section{Patients and Methods}

From April 2011 to December 2012, a total of 298 consecutive cases with gastric cancer treated by surgical resection without any preoperative therapy were retrieved from the Department of Surgery of Kosin University College of Medicine. The medical records and surgical specimens of these patients were retrospectively evaluated after obtaining approval from the Investigational Review Board of the Kosin University Gospel Hospital. The disease stage was determined according to the (AJCC)-TNM classification (seventh edition) [22]. 3 patients who had gastric cancer recurrence and 13 patients with synchronous multiple primary cancers (e.g., thyroid cancer, colon cancer, and lung cancer) were excluded from the study. The clinicopathological characteristics of each patient were retrieved from hospital information systems, retrospectively. Clinicopathological parameters, including age, gender, tumor location, histological classification, pathological TNM stage, neural invasion, lymphatic invasion, and vascular invasion status, were retrieved from medical charts or pathology reports. Histological classification was determined according to Lauren's classification and the World Health Organization (WHO) classification [23].

2.1. Immunohistochemistry (IHC). Tumor tissues were fixed in $10 \%$ formalin and embedded in paraffin. Immunohistochemical staining was carried out using anti-HER-2/neu (Dako, Glostrup, Denmark) as the primary antibody for cerbB-2. After making slices using a microtome, tissue sections $(4 \mu \mathrm{m})$ were immersed in xylene solution to remove residual paraffin and hydrated in an alcohol series. Sections were boiled for 5 minutes to retrieve antigenicity in citrate buffer $(\mathrm{pH}$ 6.0) and left for 30 minutes at room temperature. After exhausting endogenous peroxidase for 10 minutes with $\mathrm{H}_{2} \mathrm{O}_{2}$ in methyl alcohol, sections were washed thrice with phosphate-buffered saline (PBS). Sections were blocked for 30 minutes with blocking solution (Histostain kit, Zymed Company, San Francisco, CA, USA) at room temperature. Sections were then incubated with anti-HER-2/neu $(1: 200$, Dako) at room temperature. After rinsing thrice with PBS, sections were incubated with biotinylated anti-mouse IgG (1:300; Zymed). After washing, sections were incubated with avidin-alkaline phosphatase for 7 minutes at $40^{\circ} \mathrm{C}$. Sections were visualized with red chromogen at $40^{\circ} \mathrm{C}$ and counterstained using the Mayer hematoxylin method. Sections were mounted and observed under light microscopy.

2.2. Assessment of HER2 Expression. The amended c-erbB-2 scoring system was applied according to location and degree of completion of staining: 0 points: staining of $\leq 10 \%$ was equivalent; 1 point: incomplete membrane staining of $>10 \%$; 2 points: weak-to-moderate complete staining of the membrane; and 3 points: strong complete staining of the membrane. An immunohistochemistry score of $3+$ or immunohistochemistry score of $2+$ was defined as overexpression of HER2 (Figure 1). 
2.3. MUC2, MUC5AC, MUC6, and p53 Expression Profile in Gastric Carcinoma. Mucin and p53 IHC staining was performed by the tyramide signal amplification-avidin-biotin complex method [24]. We used monoclonal antibodies against MUC5AC (Novocastra, Newcastle-upon-Tyne, UK; diluted 1:100) as a marker for gastric faveolar cells, MUC6 (Novocastra; $1: 100$ ) as a marker for gastric mucous neck cells and pyloric glands, MUC2 (Novocastra; $1: 100$ ) as a marker for intestinal goblet cells, and p53 (1:100, clone DO7; Dako). The expressions of MUC2, MUC5AC, and MUC6 were regarded as positive when more than $10 \%$ of the area was positively stained [17]. Overexpression of p53 was regarded as positive when more than $10 \%$ of tumor cells displayed nuclear immunostaining [25].

2.4. Statistical Analysis. The statistical evaluation was performed using Spearman's correlation test to analyze rank date. Kaplan-Meier survival plots were generated and comparisons between survival curves were made with the log-rank statistics. Cox's proportional hazards model was used for the multivariate analysis. SPSS 18.0 software (SPSS Inc., Chicago, IL, USA) was applied to analyse all data and $P<0.05$ was considered to indicate a statistically significant difference.

\section{Results}

3.1. Demographic Characteristics. The studied population consisted of 187 men and 95 women. In the 282 cases enrolled in the study, the median age of the patients at diagnosis was 60 years (range $34-85$ years) and all patients were Korean. The demographics and tumor-related factors are summarized in Table 1. Tumor location in the stomach was lower third in 164, middle third in 71, and upper third in 45 cases, two of which were located at the gastroesophageal junction. In accordance with the World Health Organization's classification standards, 167 patients $(60.9 \%)$ had tubular adenocarcinoma and 106 patients $(37.6 \%)$ had poorly cohesive carcinoma. According to the pathological depth of tumor, 138 patients $(48.9 \%)$ were pTla, 37 (13.1\%) were pTlb, 15 (5.3\%) were pT2, 55 (19.5\%) were pT3, $36(12.8 \%)$ were pT4a, and $1(0.4 \%)$ was pT4b. Regarding the tumor stage, 158 (56.0\%) were stage I, 63 (22.3\%) stage II, 61 (15.2\%) stage III.

3.2. HER2 Status and the Results of MUC2, MUC5AC, MUC6, and $p 53$. Immunohistochemical analysis was performed to examine the expression of HER2 in all the cases. The numbers of patients with an HER2 score of $0,1+, 2+$, and 3+ were 207 (73.4\%), $24(8.5 \%), 5(1.8 \%)$, and $46(16.3 \%)$. The percent of positive stain for HER2 and p53 positive rate was $18.1 \%$ (51 of 282) and $71.9 \%(202 / 282)$. The positive rates of MUC2, MUC5AC, and MUC6 were 18.5\% (52/282), 71.9\% $(202 / 282)$, and $23.6 \%(66 / 282)$. The expression of HER2, MUC2, MUC5AC, MUC6, and p53 is summarized in Table 2.

3.3. Correlation of HER2 Status with Clinicopathological Features. The correlation between HER2 status and the clinicopathological features is shown in Table 1. The frequency of HER2 positivity correlated with WHO classification, Lauren classification, depth of tumor, nodal stage, TNM stage, and lymphatic invasion. According to Lauren's classification, HER2 overexpression was more often detected in the intestinal histological type (24.0\%) than in the diffuse type (14.0\%), indeterminate type $(28.6 \%)$, or mixed type $(2.6 \%)$. HER2 overexpression was more commonly observed in patients with lymph node metastasis (N0 disease, 13.2\%; N1 disease, 13.3\%; N2 disease, 30.3\%; N3 disease, 35.1\%; $P=0.003$ ). And differences in frequency of HER2 overexpression among the $\mathrm{T}$ stages also were estimated to be significant $(P=0.036)$. On TNM stage, HER2 overexpression was more commonly observed in patients with advanced stage $(P=0.009)$. HER2positive tumors tended to present with lymphatic invasions with statistical significance $(P=0.027)$. The presence of HER2 overexpression in the tumor was not influenced by tumor location or tumor size.

3.4. Correlation of HER2 Expression with MUC2, MUC5AC, MUC6, and p53. The results of the analysis of the expression of the three mucin markers based on mucin expression are shown in Table 2. Of the three markers, MUC2 expression and MUC6 expression were significantly correlated with HER2 positivity $(P=0.004, P=0.043)$. There was no correlation between the MUC5AC and HER2 overexpression. The p53 overexpression was significantly correlated with HER2 positivity $(P=0.034)$.

3.5. Prognostic Significance of HER2, MUC2, MUC5AC, MUC6, and p53 Expression in Gastric Carcinoma. Univariate analysis of factors related to overall survival in gastric carcinoma is summarized in Table 3. Patients with HER2 overexpression had significantly worse survival than those without HER2 overexpression ( $P=0.001)$ (Figure 2). Other factors significantly correlated with survival were Lauren classification, TNM stage, depth of invasion, nodal status, and lymphatic invasion. There was no significant difference in survival related to MUC2, MUC5AC, MUC6, and p53 expression. The five factors (HER2 overexpression, Lauren classification, depth of invasion, nodal status, and lymphatic invasion) selected from univariate analysis, based on a $P$ value $<0.05$, were entered into the Cox proportional hazards model. This multivariate analysis showed that HER2 expression $(P=0.024)$ and nodal status $(P<0.001)$ were significant risk factors affecting the outcome (Table 3 ).

\section{Discussion}

The c-erbB-2 gene is a protooncogene located on chromosome 17. It expresses HER2/neu protein, one of the epithelial growth factor receptor (EGFR) families, and has tyrosine kinase (TK) activity, which mediates cancer proliferation [26]. HER2 gene amplification and protein overexpression have been suggested as the targets for a therapy with antiHER2 humanized monoclonal antibody (trastuzumab) in various cancers; [27-35] in those studies, a very wide range of HER2 expression has been described with controversial data for most cancer types [34]. Recently, in an open-label international phase 3 randomized controlled trial (ToGA trial) undertaken in 122 centers in 24 countries, patients with 
TABLE 1: Correlation between HER2 overexpression and clinicopathologic parameters of gastric carcinoma.

\begin{tabular}{|c|c|c|c|c|}
\hline \multirow{2}{*}{ Variables } & \multirow{2}{*}{$N(\%)$} & \multicolumn{2}{|c|}{ HER2 positive } & \multirow{2}{*}{$P$ value } \\
\hline & & Positive $(\%)(n=56)$ & Negative $(\%)(n=266)$ & \\
\hline$\overline{\text { Age }^{a}}$ & $60.51 \pm 10.86$ & $59.70 \pm 9.85$ & $60.68 \pm 11.07$ & 0.540 \\
\hline Gender & & & & 0.546 \\
\hline Male & $187(66.3)$ & $34(18.2 \%)$ & $153(81.8 \%)$ & \\
\hline Female & $95(33.7)$ & $17(17.9 \%)$ & $78(82.1 \%)$ & \\
\hline Location & & & & 0.173 \\
\hline Upper & $45(16.0)$ & $12(26.7 \%)$ & $33(73.7 \%)$ & \\
\hline Middle & $71(25.2)$ & $8(11.3 \%)$ & $63(88.7 \%)$ & \\
\hline Lower & $164(58.2)$ & $31(18.9 \%)$ & $133(81.1 \%)$ & \\
\hline $\mathrm{EG})^{\mathrm{b}}$ & $4(1.2)$ & $1(25.0 \%)$ & $3(75.0 \%)$ & \\
\hline WHO classification & & & & 0.022 \\
\hline Tubular & $167(60.9)$ & $32(19.2 \%)$ & $135(80.8 \%)$ & \\
\hline Mucinous & $1(0.4)$ & $0(0.0 \%)$ & $1(100.0 \%)$ & \\
\hline Poorly cohesive & $106(37.6)$ & $15(14.2 \%)$ & $91(85.8 \%)$ & \\
\hline Papillary & $6(2.1)$ & $2(33.3 \%)$ & $4(66.7 \%)$ & \\
\hline Lauren classification & & & & 0.010 \\
\hline Intestinal & $150(53.2)$ & $36(24.0 \%)$ & $114(76.0 \%)$ & \\
\hline Diffuse & $86(30.5)$ & $12(14.0 \%)$ & $74(86.0 \%)$ & \\
\hline Mixed & $39(13.8)$ & $1(2.6 \%)$ & $38(97.4 \%)$ & \\
\hline Indeterminate & $7(2.5)$ & $2(28.6 \%)$ & $5(71.4 \%)$ & \\
\hline Size $^{\mathrm{a}}$ & $3.48 \pm 3.06$ & $3.87 \pm 3.15$ & $3.40 \pm 3.04$ & 0.293 \\
\hline Tumor size & & & & 0.176 \\
\hline $5 \mathrm{~cm}<$ & $61(21.6)$ & $14(23.0 \%)$ & $47(77.0 \%)$ & \\
\hline $5 \mathrm{~cm} \geq$ & $221(78.4)$ & $37(16.7 \%)$ & $184(83.3 \%)$ & \\
\hline Depth of tumor (T stage) & & & & 0.036 \\
\hline Tla & $138(48.9)$ & $20(14.5 \%)$ & $118(85.5 \%)$ & \\
\hline $\mathrm{Tlb}$ & $37(13.1)$ & $9(24.3 \%)$ & $28(75.7 \%)$ & \\
\hline $\mathrm{T} 2$ & $15(5.3)$ & $1(6.7 \%)$ & $14(93.3 \%)$ & \\
\hline $\mathrm{T} 3$ & $55(19.5)$ & $9(16.4 \%)$ & $46(83.6 \%)$ & \\
\hline $\mathrm{T} 4 \mathrm{a}$ & $36(12.8)$ & $11(30.6 \%)$ & $25(69.4 \%)$ & \\
\hline $\mathrm{T} 4 \mathrm{~b}$ & $1(0.4)$ & $1(100.0)$ & $0(0.0)$ & \\
\hline Nodal stage $(\mathrm{N})$ & & & & 0.003 \\
\hline No & $182(64.5)$ & $24(13.2 \%)$ & $158(86.8 \%)$ & \\
\hline N1 & $30(10.6)$ & $4(13.3 \%)$ & $26(86.7 \%)$ & \\
\hline $\mathrm{N} 2$ & $33(11.7)$ & $10(30.3 \%)$ & $23(69.7 \%)$ & \\
\hline N3 & $37(13.1)$ & $13(35.1 \%)$ & $24(64.9 \%)$ & \\
\hline Stage (TNM) & & & & 0.027 \\
\hline I & $158(56.0)$ & $22(13.9 \%)$ & $136(86.1 \%)$ & \\
\hline II & $63(22.3)$ & $11(17.5 \%)$ & $52(82.5 \%)$ & \\
\hline III & $61(21.7)$ & $18(29.5 \%)$ & $43(70.5 \%)$ & \\
\hline Neural invasion & & & & 0.345 \\
\hline Yes & $56(21.0)$ & $8(14.3 \%)$ & $48(85.7 \%)$ & \\
\hline No & $211(79.0)$ & $43(20.4 \%)$ & $168(79.6 \%)$ & \\
\hline Lymphatic invasion & & & & 0.011 \\
\hline Yes & $83(31.1)$ & $24(28.9 \%)$ & $59(71.1 \%)$ & \\
\hline No & $184(68.9)$ & $27(14.7 \%)$ & $157(85.3 \%)$ & \\
\hline Vascular invasion & & & & 0.105 \\
\hline Yes & $14(5.2)$ & $5(35.7 \%)$ & $9(64.3 \%)$ & \\
\hline No & $253(94.8)$ & $46(18.2 \%)$ & $207(81.8 \%)$ & \\
\hline Recurrence & & & & 0.005 \\
\hline Yes & $31(11.0)$ & $12(38.7 \%)$ & $19(61.3 \%)$ & \\
\hline No & $251(89.0)$ & $39(15.5 \%)$ & $212(84.5 \%)$ & \\
\hline
\end{tabular}

\footnotetext{
${ }^{a}$ Age and size were reported as the mean \pm SD.
}

${ }^{\mathrm{b}}$ Esophagogastric junction. 
TABLE 2: Correlation of HER2 overexpression with MUC2, MUC5AC, MUC6, and p53.

\begin{tabular}{ccccc}
\hline \multicolumn{5}{c}{ HER2 positive } \\
Variables & $N(\%)$ & $\begin{array}{c}\text { Positive (\%) } \\
(n=51)\end{array}$ & $\begin{array}{c}\text { Negative (\%) } \\
(n=231)\end{array}$ & $P$ value \\
\hline p53 & & & $\mathbf{0 . 0 3 4}$ \\
Positive & $210(74.5 \%)$ & $44(21.0 \%)$ & $166(79.0 \%)$ & \\
Negative & $72(25.5 \%)$ & $7(9.7 \%)$ & $65(90.3 \%)$ & \\
MUC2 & & & & $\mathbf{0 . 0 0 4}$ \\
Positive & $52(18.5 \%)$ & $17(32.7 \%)$ & $35(67.3 \%)$ & \\
Negative & $229(81.5 \%)$ & $33(14.4 \%)$ & $196(85.6 \%)$ & \\
MUC5AC & & & & 0.731 \\
Positive & $202(71.9 \%)$ & $39(17.4 \%)$ & $167(82.7 \%)$ & \\
Negative & $79(28.1 \%)$ & $16(16.7 \%)$ & $64(81.0 \%)$ & \\
MUC6 & & & & $\mathbf{0 . 0 4 3}$ \\
Positive & $64(22.9 \%)$ & $17(26.6 \%)$ & $47(73.4 \%)$ & \\
Negative & $216(77.1 \%)$ & $33(15.3 \%)$ & $183(84.7 \%)$ & \\
\hline
\end{tabular}

TABLE 3: Univariate and multivariate analysis of clinicopathological variables for the survival of the patients with gastric carcinoma.

\begin{tabular}{lcc}
\hline Variables & Relative risk $(95 \%$ CI $)$ & $P$ value \\
\hline Univariate & $5.317(2.936-9.630)$ & $P<\mathbf{0 . 0 0 1}$ \\
TNM stage & $2.962(1.051-8.345)$ & $P=\mathbf{0 . 0 4 0}$ \\
Tumor size $(5 \mathrm{~cm}<)$ & $2.453(1.649-3.647)$ & $P<\mathbf{0 . 0 0 1}$ \\
Depth of invasion (T3-T4) & $3.973(2.375-6.647)$ & $P<\mathbf{0 . 0 0 1}$ \\
Nodal status (N stage) & $0.287(0.080-1.024)$ & $P=\mathbf{0 . 0 5 4}$ \\
p53 expression $(+)$ & $1.786(0.565-5.640)$ & $P=0.323$ \\
MUC2 expression $(+)$ & $1.728(0.488-6.125)$ & $P=0.397$ \\
MUC5AC expression $(+)$ & $1.257(0.397-3.977)$ & $P=0.697$ \\
MUC6 expression $(+)$ & $4.673(1.690-12.922)$ & $P=\mathbf{0 . 0 0 3}$ \\
HER2 overexpression $(+)$ & $1.914(1.099-3.337)$ & $P=\mathbf{0 . 0 2 2}$ \\
Lauren classification & $12.218(4.143-36.029)$ & $P<\mathbf{0 . 0 0 1}$ \\
Vascular invasion $(+)$ & $17.917(4.033-79.610)$ & $P<\mathbf{0 . 0 0 1}$ \\
Lymphatic invasion $(+)$ & $5.049(1.830-13.926)$ & $P=\mathbf{0 . 0 0 2}$ \\
Neural invasion $(+)$ & $3.394(1.173-9.819)$ & $P=\mathbf{0 . 0 2 4}$ \\
$\quad$ Multivariate: Cox regressional hazard model & \\
HER2 overexpression $(+)$ & $3.840(2.278-6.473)$ & $P<\mathbf{0 . 0 0 1}$ \\
Nodal status (N stage) &
\end{tabular}

advanced gastric or gastroesophageal junction carcinomas have been studied in order to verify if their tumors showed overexpression of HER2 protein by immunohistochemistry or gene amplification by fluorescence in situ hybridization (FISH) [9]. In ToGA study, the HER2-positive ratio was higher in tumors at the gastroesophageal junction than in gastric cancer (33.2 versus 20.9\%). However, it has been shown that the addition of trastuzumab to chemotherapy improved survival in patients with advanced gastric or gastroesophageal junction carcinomas compared with chemotherapy alone [9, 36-38].

Since the overexpression of HER2 in gastric cancer was first published in 1986 [39], many studies have reported

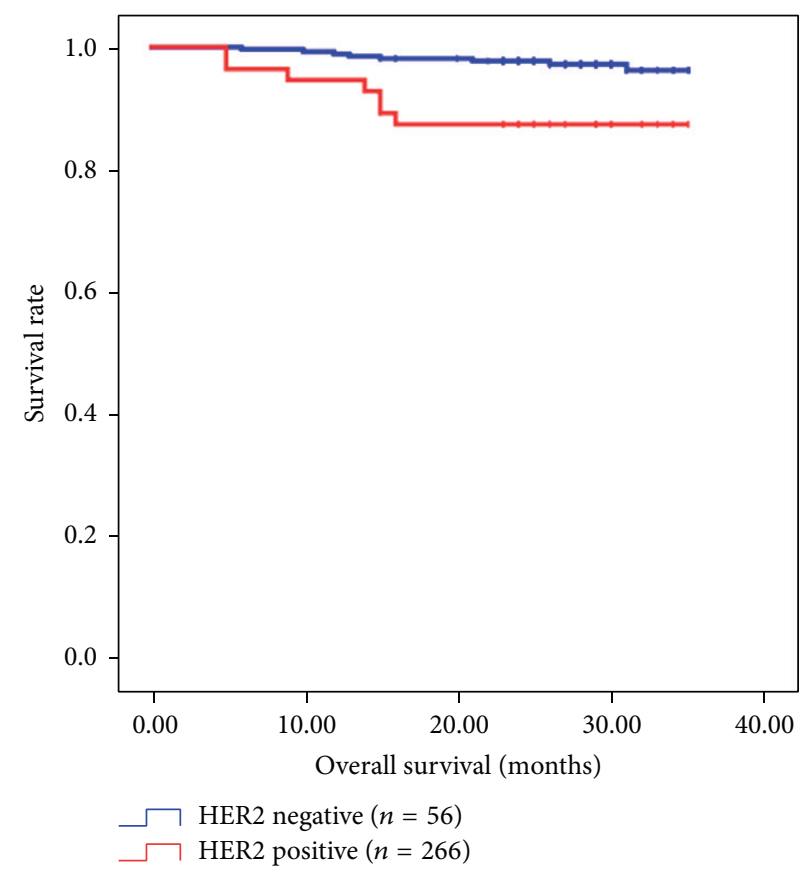

FIGURE 2: Kaplan-Meier survival curves according to the HER2 overexpression in patients with gastric carcinoma.

the frequency of HER2 positivity in gastric cancer patients from various regions throughout the world. According to the review by Jorgensen and Hersom [8], the positive rate ranged from $4 \%$ to $53 \%$ by IHC alone and from $9 \%$ to $18 \%$ when ISH (in situ hybridization) was included. But according to what was reported by Sheng et al. [40], detected by both IHC and ISH, the HER2-positive rate was $13 \%$. In the present study, the rate of HER2 positivity was estimated to be $18.1 \%$. Of the 51 HER2-positive tumors in the present study, 36 were of intestinal type and 12 were of diffuse type according to Lauren's classification. These data are consistent with previous reports that the intestinal type showed a higher rate of HER2 positivity than the diffuse/mixed type [37, 41-47]. A strong correlation between HER2 positivity and intestinal histological type is also supported by our finding. Furthermore, HER2 overexpression was related to depth of invasion of tumor, lymph node metastasis, pTNM stage, and lymphatic invasion presenting aggressive features of the tumor (Table 2). Lymph node metastasis was significantly more frequent in patients with poorly differentiated tumor histology. Several previous studies have reported the existence of a relationship between the presence of lymph node metastasis and tumor HER2 overexpression $[42,48]$. This finding suggests that tumor biology in the subgroup of patients with tumor HER2 overexpression predisposes to spread via the lymphatic system. This finding suggests the potential clinical benefit of HER2targeted therapy in the adjuvant or neoadjuvant setting for patients with node-positive gastric cancer.

In breast cancer, overexpression of the HER2 gene was associated with poor outcomes, higher mortality, and increased higher recurrence and metastasis $[1,49,50]$. It has been generally reported that HER2 overexpression is 
correlated with aggressive biological behavior and poor prognosis, despite some contradictory results in gastric carcinoma $[2,5,45,51-60]$. Our study confirmed that the HER2 positivity was associated with lymphatic invasion and lymph node metastases (including $\mathrm{pN}$ stage) in agreement with previous studies [53, 54, 56, 59, 61]. Our findings suggest that HER2 overexpression is associated with a progression of gastric cancer.

However, the association between HER2 status and prognosis in gastric cancer remains controversial, and a correlation between HER2 amplification or overexpression and favorable survival has only been shown in a few studies $[9,62$, 63]. Some studies have indicated that HER2 overexpression is strongly associated with differentiated or intestinal type gastric cancers, which generally have a better prognosis than undifferentiated or diffuse type cancers. This may be the major source of controversies surrounding the prognostic value of HER2 overexpression. But most published studies assessing this association have shown a poor prognosis in HER2-positive gastric cancers. In our study, HER2 overexpression was correlated with poor prognosis.

The present study has examined the association between the mucin markers and HER2 status of gastric cancer. Of the three mucin markers that we examined, the expression of MUC2 (goblet cells) and MUC6 (mucous neck cells, pyloric glands) was significantly correlated with HER2 positivity.

Because MUC2 was strongly correlated with the intestinal histological type in our study $(P=0.004)$, it seems that the correlation between MUC2 and HER2 expression may reflect a linkage between the intestinal differentiation of cancer cells and HER2 expression.

The $p 53$ gene is also located on chromosome 17 like the c-erbB-2 gene. It is a representative tumor suppressor gene, and mutations of this gene are found out in most tumors originating from the gastrointestinal system, urogenital system, and skin [64]. The wild-type p53 gene is involved in the differentiation, proliferation, and apoptosis of cells, whereas the mutant type is considered to be the cause of atypical cell growth [65]. Accumulation of p53 protein in the nuclei of carcinoma cells is known to correlate well with the presence of mutations in the $p 53$ gene $[36,38]$. Our study demonstrated a strong correlation between p53 overexpression and HER2 positivity, suggesting a possible role of p53 abnormality in the development of HER2-positive gastric cancer. These findings are consistent with previous studies, which have reported a correlation between $\mathrm{p} 53$ nuclear staining and HER2 positivity $[19,21]$. Intriguingly, some studies also reported a linkage between alterations of $\mathrm{p} 53$ and the intestinal histological type. Consistently, our study confirmed that p53 overexpression was more often found in the intestinal type of gastric cancer $[25,53]$. These results suggest that the intestinal differentiation of cancer cells, as well as HER2 and MUC2 expression, may also be linked to the expression of p53. The significance of the expression of these molecules in regard to tumor biology and prognosis needs to be determined by further studies.

This study had some limitations. Even though we focused on gastric cancer treated by curative resection, we could not evaluate the effect of adjuvant chemotherapy. Most early stage gastric cancer patients were not treated with adjuvant chemotherapy, and patients with more advanced stages were treated with heterogeneous adjuvant chemotherapy protocol. The influence of tumor location was not analyzed due to the small number of cardiac origin patients $(0.6 \%)$ included in this study There is a relatively low incidence of proximal gastric cancer in Asian patients compared to the incidence in Western countries. Therefore, there were too few patients to evaluate differences in tumor location. And this study includes the relatively short follow-up time, particularly for maintenance of oncologic issues. A long term followup is needed to determine the association between HER2 expression and the mucin markers and p53 of gastric cancer prognosis.

\section{Conclusion}

In summary, we assessed the HER2 status in 282 samples from consecutive surgical cases of gastric cancer. The total HER2-positive rate was $18.1 \%$. HER2 overexpression was correlated with Lauren classification, TNM stage, depth of invasion, nodal status, and lymphatic invasion. And MUC2 and MUC6 were significantly correlated with HER2 positivity. HER2 status was found to be associated with several clinicopathological characteristics related to the invasive behavior of gastric cancer, especially lymph node metastasis and lymphatic invasion. This finding suggests the potential clinical benefit of HER2-targeted therapy in the adjuvant or neoadjuvant setting for patients with node-positive gastric cancer.

And this study shows that HER2 overexpression is an independent poor prognostic factor in gastric carcinoma. Therefore, HER2 expression may be a useful marker to predict the outcome of patients with surgically resected gastric carcinoma.

\section{Conflict of Interests}

The authors declare that there is no conflict of interests regarding the publication of this paper.

\section{References}

[1] D. J. Slamon, G. M. Clark, S. G. Wong, W. J. Levin, A. Ullrich, and W. L. McGuire, "Human breast cancer: correlation of relapse and survival with amplification of the HER-2/neu oncogene," Science, vol. 235, no. 4785, pp. 177-182, 1987.

[2] J. D. Barros-Silva, D. Leitão, L. Afonso et al., "Association of ERBB2 gene status with histopathological parameters and disease-specific survival in gastric carcinoma patients," British Journal of Cancer, vol. 100, no. 3, pp. 487-493, 2009.

[3] J. T. Jørgensen, “Targeted HER2 treatment in advanced gastric cancer," Oncology, vol. 78, no. 1, pp. 26-33, 2010.

[4] M. Nakajima, H. Sawada, Y. Yamada et al., "The prognostic significance of amplification and overexpression of c-met and c-erb B-2 in human gastric carcinomas," Cancer, vol. 85, no. 9, pp. 1894-1902, 1999.

[5] D. I. Park, J. W. Yun, J. H. Park et al., "HER-2/neu amplification is an independent prognostic factor in gastric cancer," Digestive Diseases and Sciences, vol. 51, no. 8, pp. 1371-1379, 2006. 
[6] M. Tanner, M. Hollmén, T. T. Junttila et al., "Amplification of HER-2 in gastric carcinoma: association with Topoisomerase IIalpha gene amplification, intestinal type, poor prognosis and sensitivity to trastuzumab," Annals of Oncology, vol. 16, no. 2, pp. 273-278, 2005.

[7] G. Z. Yu, Y. Chen, and J. J. Wang, "Overexpression of Grb2/HER2 signaling in Chinese gastric cancer: their relationship with clinicopathological parameters and prognostic significance," Journal of Cancer Research and Clinical Oncology, vol. 135, no. 10, pp. 1331-1339, 2009.

[8] J. T. Jorgensen and M. Hersom, "HER2 as a prognostic marker in gastric cancer: a systematic analysis of data from the literature," Journal of Cancer, vol. 3, no. 1, pp. 137-144, 2012.

[9] Y.-J. Bang, E. van Cutsem, A. Feyereislova et al., "Trastuzumab in combination with chemotherapy versus chemotherapy alone for treatment of HER2-positive advanced gastric or gastrooesophageal junction cancer (ToGA): a phase 3, open-label, randomised controlled trial," The Lancet, vol. 376, no. 9742, pp. 687-697, 2010.

[10] M. Horner, L. Ries, M. Krapcho et al., SEER Cancer Statistics Review, 1975-2006, National Cancer Institute, Bethesda, Md, USA, 2009.

[11] M. A. Hollingsworth and B. J. Swanson, "Mucins in cancer: protection and control of the cell surface," Nature Reviews Cancer, vol. 4, no. 1, pp. 45-60, 2004.

[12] M. C. Rose and J. A. Voynow, "Respiratory tract mucin genes and mucin glycoproteins in health and disease," Physiological Reviews, vol. 86, no. 1, pp. 245-278, 2006.

[13] S. Yonezawa, M. Higashi, N. Yamada et al., "Mucins in human neoplasms: clinical pathology, gene expression and diagnostic application," Pathology International, vol. 61, no. 12, pp. 697-716, 2011.

[14] P. D. Vermeer, L. A. Einwalter, T. O. Moninger et al., "Segregation of receptor and ligand regulates activation of epithelial growth factor receptor," Nature, vol. 422, no. 6929, pp. 322-326, 2003.

[15] S. B. Ho, L. L. Shekels, N. W. Toribara et al., "Mucin gene expression in normal, preneoplastic, and neoplastic human gastric epithelium," Cancer Research, vol. 55, no. 12, pp. 26812690, 1995.

[16] B. Kocer, A. Soran, G. Kiyak et al., "Prognostic significance of mucin expression in gastric carcinoma," Digestive Diseases and Sciences, vol. 49, no. 6, pp. 954-964, 2004.

[17] K. Wakatsuki, Y. Yamada, M. Narikiyo et al., "Clinicopathological and prognostic significance of mucin phenotype in gastric cancer," Journal of Surgical Oncology, vol. 98, no. 2, pp. 124-129, 2008.

[18] H. Yokozaki, H. Kuniyasu, Y. Kitadai et al., "p53 point mutations in primary human gastric carcinomas," Journal of Cancer Research and Clinical Oncology, vol. 119, no. 2, pp. 67-70, 1992.

[19] M. S. Al-Moundhri, V. Nirmala, I. Al-Hadabi et al., "The prognostic significance of p53, p27kip1, p21waf1, HER-2/neu, and Ki67 proteins expression in gastric cancer: a clinicopathological and immunohistochemical study of 121 Arab patients," Journal of Surgical Oncology, vol. 91, no. 4, pp. 243-252, 2005.

[20] M. Hollstein, K. Rice, M. S. Greenblatt et al., "Database of p53 gene somatic mutations in human tumors and cell lines," Nucleic Acids Research, vol. 22, no. 17, pp. 3551-3555, 1994.

[21] K. E. Lee, H.-J. Lee, Y. H. Kim et al., "Prognostic significance of p53, nm23, PCNA and c-erbB-2 in gastric cancer," Japanese Journal of Clinical Oncology, vol. 33, no. 4, pp. 173-179, 2003.
[22] S. B. Edge and C. C. Compton, "The American Joint Committee on Cancer: the 7th edition of the AJCC cancer staging manual and the future of TNM," Annals of Surgical Oncology, vol. 17, no. 6, pp. 1471-1474, 2010.

[23] F. T. Bosman, W. H. Organization, F. Carneiro, and R. H. Hruban, WHO Classification of Tumours of the Digestive System, International Agency for Research on Cancer (IARC) (UN), 2010.

[24] Y. Toda, K. Kono, H. Abiru et al., "Application of tyramide signal amplification system to immunohistochemistry: a potent method to localize antigens that are not detectable by ordinary method," Pathology International, vol. 49, no. 5, pp. 479-483, 1999.

[25] H. M. Ismail, M. Moneer, M. El-Baradie, O. Khorshid, and A. Touny, "Clinicopathologic and prognostic significance of overexpression of her-2/neu and p53 oncoproteins in gastric carcinoma using tissue microarray," Journal of the Egyptian National Cancer Institute, vol. 19, no. 2, pp. 147-157, 2007.

[26] A. L. Schechter, D. F. Stern, L. Vaidyanathan et al., "The neu oncogene: an erb-B-related gene encoding a 185,000-M(r) tumour antigen," Nature, vol. 312, no. 5994, pp. 513-516, 1984.

[27] R. Haddad, A. D. Colevas, J. F. Krane et al., "Herceptin in patients with advanced or metastatic salivary gland carcinomas. A phase II study," Oral Oncology, vol. 39, no. 7, pp. 724-727, 2003.

[28] D. E. Hansel, R. Ashfaq, A. Rahman et al., "A subset of pancreatic adenocarcinomas demonstrates coamplification of topoisomerase II $\alpha$ and HER2/neu: use of immunolabeling and multicolor FISH for potential patient screening and treatment," The American Journal of Clinical Pathology, vol. 123, no. 1, pp. 28-35, 2005.

[29] Z. Latif, A. D. Watters, J. M. S. Bartlett, M. A. Underwood, and M. Aitchison, "Gene amplification and over-expression of HER2 in renal cell carcinoma," BJU International, vol. 89, no. 1, pp. 5-9, 2002.

[30] Z. Latif, A. D. Watters, I. Dunn, K. Grigor, M. A. Underwood, and J. M. S. Bartlett, "HER2/neu gene amplification and protein overexpression in G3 pT2 transitional cell carcinoma of the bladder: a role for anti-HER2 therapy?" European Journal of Cancer, vol. 40, no. 1, pp. 56-63, 2004.

[31] B. Leyland-Jones, "Trastuzumab therapy for the metastatic patient: does the primary match?” Annals of Oncology, vol. 13, no. 7, pp. 993-994, 2002.

[32] J. D. Oxley, M. H. Winkler, D. A. Gillatt, and D. S. Peat, "Her2/neu oncogene amplification in clinically localised prostate cancer," Journal of Clinical Pathology, vol. 55, no. 2, pp. 118-120, 2002.

[33] J. S. Ross and B. J. McKenna, "The HER-2/neu oncogene in tumors of the gastrointestinal tract," Cancer Investigation, vol. 19, no. 5, pp. 554-568, 2001.

[34] C. Tapia, S. Savic, U. Wagner et al., "HER2 gene status in primary breast cancers and matched distant metastases," Breast Cancer Research, vol. 9, no. 3, article R31, 2007.

[35] K. Ugocsai, L. Mándoky, L. Tiszlavicz, and J. Molnár, "Investigation of HER2 overexpression in non-small cell lung cancer," Anticancer Research, vol. 25, no. 4, pp. 3061-3066, 2005.

[36] A. J. Levine, "p53, the cellular gatekeeper for growth and division," Cell, vol. 88, no. 3, pp. 323-331, 1997.

[37] C. B. Moelans, A. N. Milne, F. H. Morsink, G. J. A. Offerhaus, and P. J. van Diest, "Low frequency of HER2 amplification and overexpression in early onset gastric cancer," Cellular Oncology, vol. 34, no. 2, pp. 89-95, 2011. 
[38] M. Oren, "Lonely no more: p53 finds its kin in a tumor suppressor haven," Cell, vol. 90, no. 5, pp. 829-832, 1997.

[39] K. Sakai, S. Mori, T. Kawamoto et al., "Expression of epidermal growth factor receptors on normal human gastric epithelia and gastric carcinomas," Journal of the National Cancer Institute, vol. 77, no. 5, pp. 1047-1052, 1986.

[40] W. Q. Sheng, D. Huang, J. M. Ying et al., "HER2 status in gastric cancers: a retrospective analysis from four Chinese representative clinical centers and assessment of its prognostic significance," Annals of Oncology, vol. 24, no. 9, Article ID mdt232, pp. 2360-2364, 2013.

[41] J. E. Boers, H. Meeuwissen, and N. Methorst, "HER2 status in gastro-oesophageal adenocarcinomas assessed by two rabbit monoclonal antibodies (SP3 and 4B5) and two in situ hybridization methods (FISH and SISH)," Histopathology, vol. 58, no. 3, pp. 383-394, 2011.

[42] S.-A. Im, J. W. Kim, J.-S. Kim et al., "Clinicopathologic characteristics of patients with stage III/IV (M0) advanced gastric cancer, according to HER2 status assessed by immunohistochemistry and fluorescence in situ hybridization," Diagnostic Molecular Pathology, vol. 20, no. 2, pp. 94-100, 2011.

[43] M. A. Kim, E. J. Jung, H. S. Lee et al., "Evaluation of HER-2 gene status in gastric carcinoma using immunohistochemistry, fluorescence in situ hybridization, and real-time quantitative polymerase chain reaction," Human Pathology, vol. 38, no. 9, pp. 1386-1393, 2007.

[44] P. L. Kunz, A. Mojtahed, G. A. Fisher et al., "HER2 expression in gastric and gastroesophageal junction adenocarcinoma in a US population: clinicopathologic analysis with proposed approach to HER2 assessment," Applied Immunohistochemistry and Molecular Morphology, vol. 20, no. 1, pp. 13-24, 2012.

[45] A. H. Marx, L. Tharun, J. Muth et al., "HER-2 amplification is highly homogenous in gastric cancer," Human Pathology, vol. 40, no. 6, pp. 769-777, 2009.

[46] B. Yan, E. X. Yau, S. S. B. Omar et al., "A study of HER2 gene amplification and protein expression in gastric cancer," Journal of Clinical Pathology, vol. 63, no. 9, pp. 839-842, 2010.

[47] S. Y. Yan, Y. Hu, J. G. Fan et al., "Clinicopathologic significance of HER-2/neu protein expression and gene amplification in gastric carcinoma," World Journal of Gastroenterology, vol. 17, no. 11, pp. 1501-1506, 2011.

[48] K. C. Kim, Y. W. Koh, H.-M. Chang et al., "Evaluation of HER2 protein expression in gastric carcinomas: comparative analysis of 1414 cases of whole-tissue sections and 595 cases of tissue microarrays," Annals of Surgical Oncology, vol. 18, no. 10, pp. 2833-2840, 2011.

[49] R. Seshadri, D. J. Horsfall, F. Firgaira et al., "The relative prognostic significance of total cathepsin D and HER-2/neu oncogene amplification in breast cancer," International Journal of Cancer, vol. 56, no. 1, pp. 61-65, 1994.

[50] S. Toikkanen, H. Helin, J. Isola, and H. Joensuu, "Prognostic significance of HER-2 oncoprotein expression in breast cancer: a 30-year follow-up," Journal of Clinical Oncology, vol. 10, no. 7, pp. 1044-1048, 1992.

[51] H. Allgayer, R. Babic, K. U. Gruetzner, A. Tarabichi, F. W. Schildberg, and M. M. Heiss, "c-erbB-2 is of independent prognostic relevance in gastric cancer and is associated with the expression of tumor-associated protease systems," Journal of Clinical Oncology, vol. 18, no. 11, pp. 2201-2209, 2000.

[52] H. Grabsch, S. Sivakumar, S. Gray, H. E. Gabbert, and W. Müller, "HER2 expression in gastric cancer: rare, heterogeneous and of no prognostic value-conclusions from 924 cases of two independent series," Cellular Oncology, vol. 32, no. 1-2, pp. 5765, 2010.

[53] H. R. Lee, J.-H. Kim, H. D. Uhm et al., "Overexpression of c-ErbB-2 protein in gastric cancer by immunohistochemical stain," Oncology, vol. 53, no. 3, pp. 192-197, 1996.

[54] J. Pinto-de-Sousa, L. David, R. Almeida et al., "c-erb B-2 expression is associated with tumor location and venous invasion and influences survival of patients with gastric carcinoma," International Journal of Surgical Pathology, vol. 10, no. 4, pp. 247-256, 2002.

[55] H. Sasano, F. Date, A. Imatani, S. Asaki, and H. Nagura, "Double immunostaining for c-erbB-2 and p53 in human stomach cancer cells," Human Pathology, vol. 24, no. 6, pp. 584-589, 1993.

[56] C.-T. Shun, M.-S. Wu, J.-T. Lin et al., "Relationship of p53 and c-erbB-2 expression to histopathological features, Helicobacter pylori infection and prognosis in gastric cancer," HepatoGastroenterology, vol. 44, no. 14, pp. 604-609, 1997.

[57] M. Tateishi, T. Toda, Y. Minamisono, and S. Nagasaki, "Clinicopathological significance of c-erbB-2 protein expression in human gastric carcinoma," Journal of Surgical Oncology, vol. 49, no. 4, pp. 209-212, 1992.

[58] S. Uchino, H. Tsuda, K. Maruyama et al., "Overexpression of cerbB-2 protein in gastric cancer. Its correlation with long-term survival of patients," Cancer, vol. 72, no. 11, pp. 3179-3184, 1993.

[59] Y. Yonemura, I. Ninomiya, A. Yamaguchi et al., "Evaluation of immunoreactivity for erbB-2 protein as a marker of poor short term prognosis in gastric cancer," Cancer Research, vol. 51, no. 3, pp. 1034-1038, 1991.

[60] X. L. Zhang, Y. S. Yang, D. P. Xu et al., "Comparative study on overexpression of Her2/Neu and Her3 in gastric cancer," World Journal of Surgery, vol. 33, no. 10, pp. 2112-2118, 2009.

[61] Y. Yonemura, I. Ninomiya, S. Ohoyama et al., "Correlation of cerbB-2 protein expression and lymph node status in early gastric cancer," Oncology, vol. 49, no. 5, pp. 363-367, 1992.

[62] C. Gómez-Martin, E. Garralda, M. José Echarri et al., "HER2/neu testing for anti-HER2-based therapies in patients with unresectable and/or metastatic gastric cancer," Journal of Clinical Pathology, vol. 65, no. 8, pp. 751-757, 2012.

[63] S. Jain, M. I. Filipe, W. J. Gullick, J. Linehan, and R. W. Morris, "c-erbB-2 proto-oncogene expression and its relationship to survival in gastric carcinoma: an immunohistochemical study on archival material," International Journal of Cancer, vol. 48, no. 5, pp. 668-671, 1991.

[64] T. Hernandez-Boussard, P. Rodriguez-Tome, R. Montesano, and P. Hainaut, "IARC p53 mutation database: a relational database to compile and analyze p53 mutations in human tumors and cell lines. International Agency for Research on Cancer," Human Mutation, vol. 14, no. 1, pp. 1-8, 1999.

[65] T. Matozaki, C. Sakamoto, T. Suzuki et al., "p53 gene mutations in human gastric cancer: Wild-type p53 but not mutant p53 suppresses growth of human gastric cancer cells," Cancer Research, vol. 52, no. 16, pp. 4335-4341, 1992. 


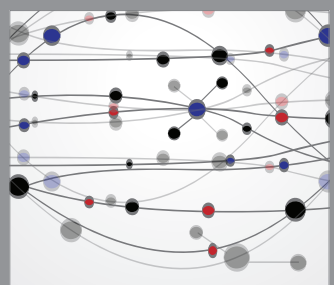

The Scientific World Journal
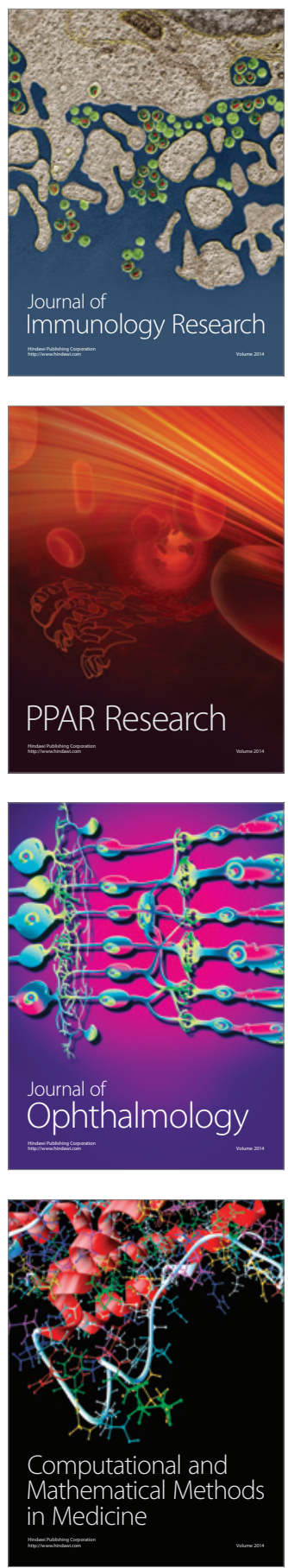

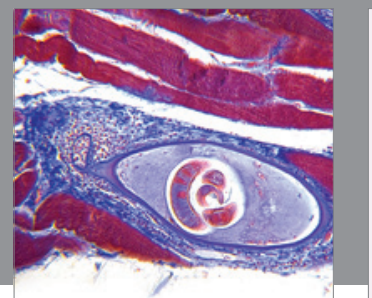

Gastroenterology

Research and Practice
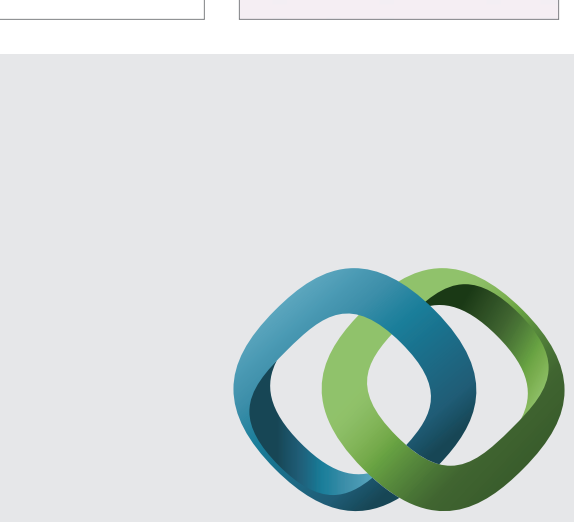

\section{Hindawi}

Submit your manuscripts at

http://www.hindawi.com
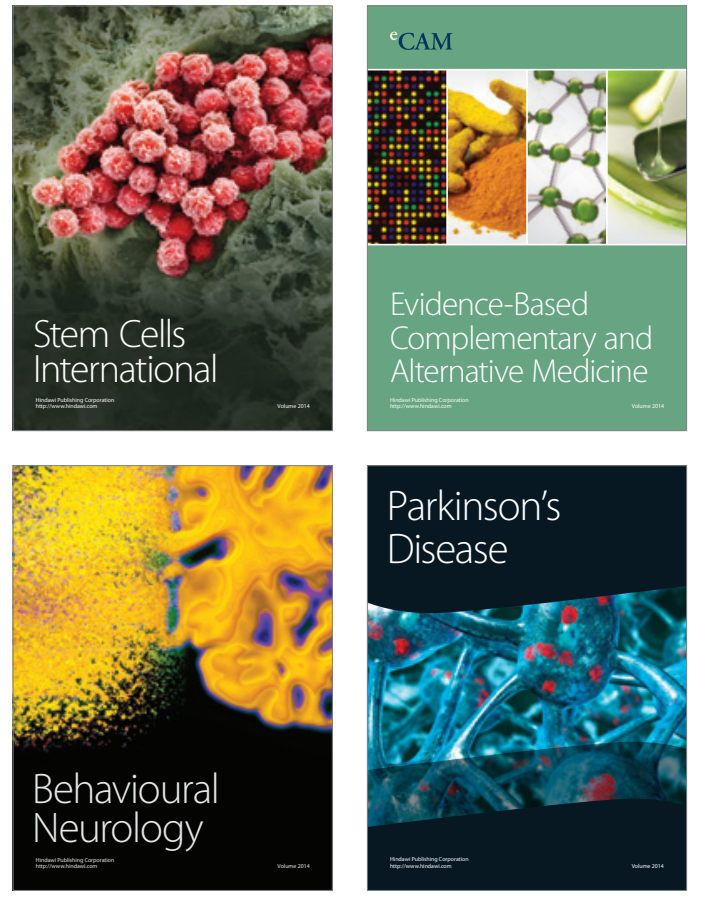
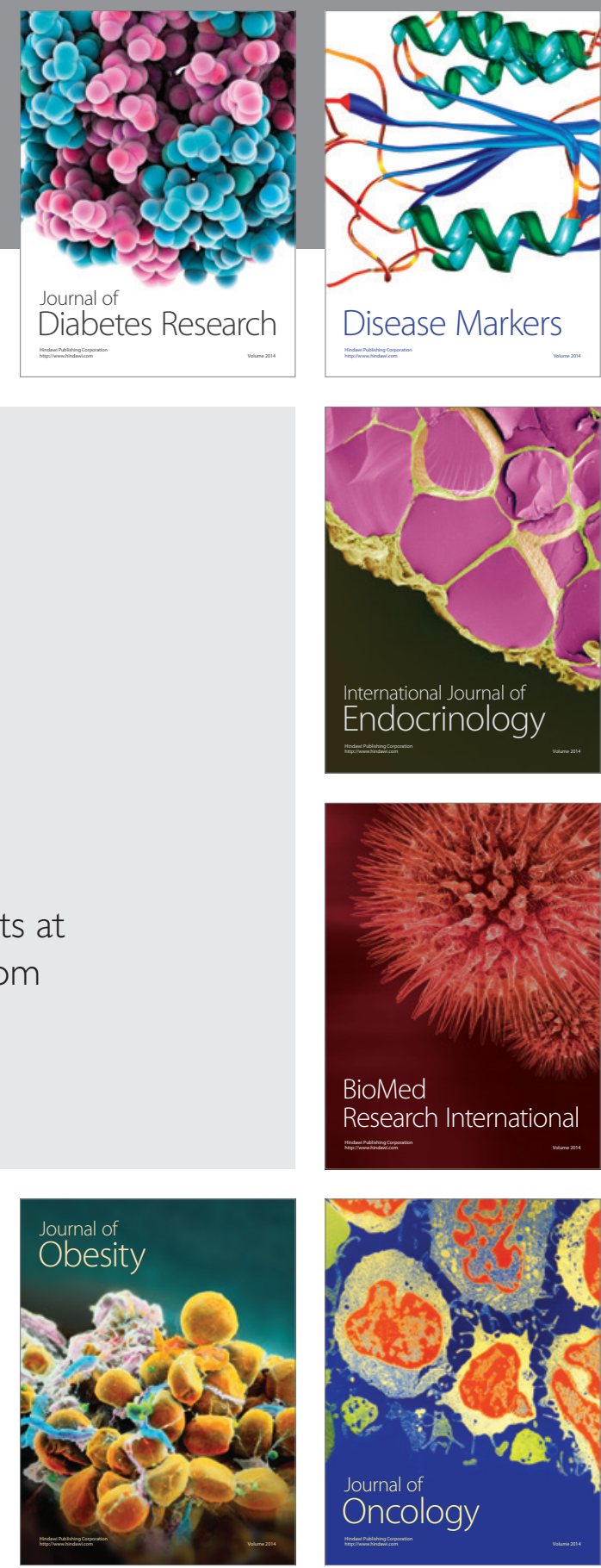

Disease Markers
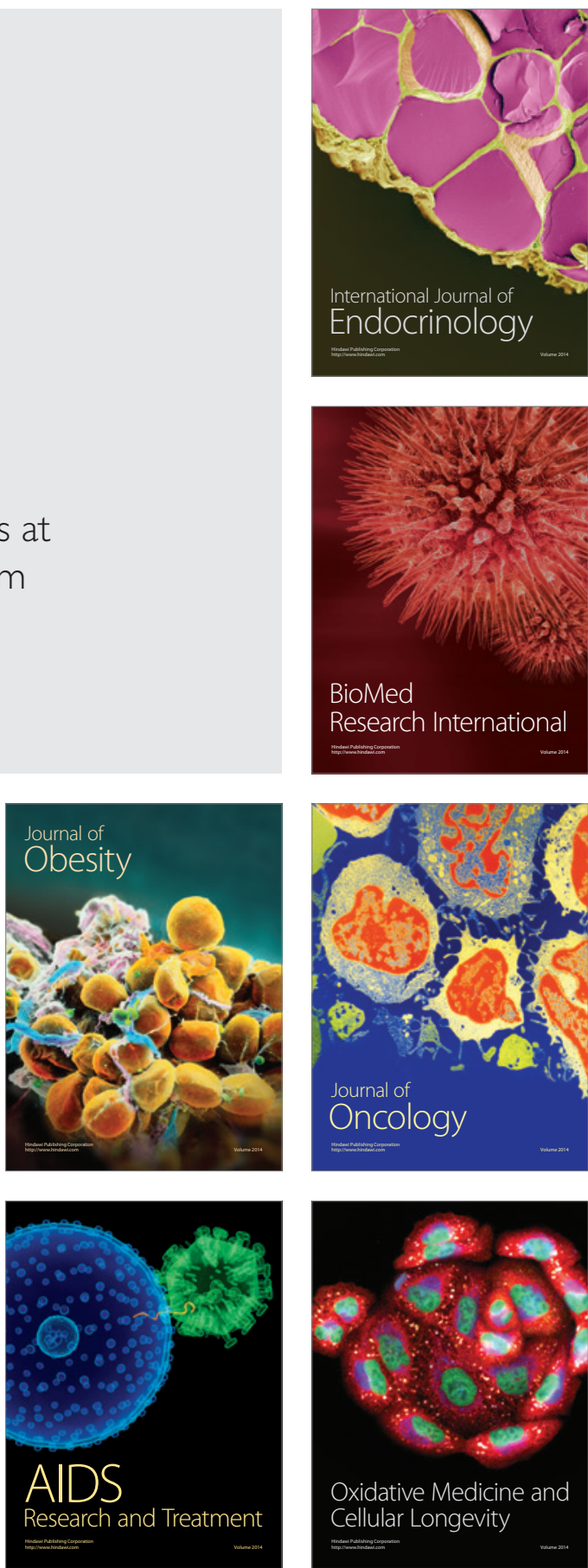